\title{
Assessing the impact of soil surface characteristics on vineyard erosion from very high spatial resolution aerial images (Côte de Beaune, Burgundy, France)
}

\author{
Amélie Quiquerez ${ }^{\mathrm{a}, *}$, Emmanuel Chevigny ${ }^{\mathrm{a}}$, Pascal Allemand ${ }^{\mathrm{b}}$, Pierre Curmi ${ }^{\mathrm{c}}$, \\ Christophe Petit ${ }^{\mathrm{d}}$, Philippe Grandjean ${ }^{\mathrm{b}}$ \\ a UMR CNRS 6298, ARTeHIS, Université de Bourgogne, 6, Boulevard Gabriel, 21000 Dijon, France \\ b UMR CNRS 5276, LGL TPE, Université Claude Bernard Lyon 1, ENS Lyon, 69622 Villeurbanne Cedex, France \\ c Agrosup, UMR 1347 Agroécologie, BP 86510, F-21000 Dijon, France \\ d UMR CNRS 7041 ARSCAN, Paris 1 Panthéon Sorbonne, 3 rue Michelet, 75005, Paris, France
}

\section{A R T I C L E I N F O}

\section{Article history:}

Received 21 March 2013

Received in revised form 28 November 2013

Accepted 2 December 2013

\section{Keywords:}

Topsoil mapping

Erosion

Remote sensing

Very high spatial resolution

Unmanned aerial vehicle

Vineyards

\begin{abstract}
A B S T R A C T
We describe a new method to map intra-plot soil surface heterogeneities at a $5 \mathrm{~cm}$ spatial resolution. Our approach unites aerial image classification acquired at very high spatial resolution (VHSR) with local soil sampling. VHSR aerial image processing, based on image classification, allows precise mapping of the spatial distribution of soil surfaces; soil sampling defines soil typology by physical and chemical characteristics. This method has been applied to a plot area located on the hillslopes of Burgundy vineyards (Monthelie, France), where decennial erosion data were already available, in order to assess the effect of soil surface characteristics and slope angle on erosion intensity and localisation. From this method, four classes of radiance were distinguished and interpreted as four soil surface state classes (SSC), defining specific areas within the studied plot. These SSCs have been characterised by their grain-size distribution, their organic carbon, calcium carbonate, and total nitrogen contents.

By allowing soil surface states to be mapped at five centimetre resolution, this approach provides novel insights into the characterisation of soil patterns and into erosion analysis on cultivated hillslopes. Our work shows that the spatial distribution of soil erosion is related to the local slope steepness but also to the spatial distribution of stoniness that results from water and tillage erosion processes.
\end{abstract}

\section{Introduction}

Although vineyards cover an only small portion of the Earth's surface, they provide an excellent example of an erosive land-use context. Vineyards undergo substantial soil loss, ten to thousand tonnes per hectare per year, in comparison with other types of agricultural land (Boardman and Poesen, 2006; Brenot et al., 2008; Cerdan et al., 2010; Hooke, 2006; Krause et al., 2003; Le Bissonnais et al., 2002; Paroissien et al., 2010). They epitomise a situation where soil sustainability is threatened, leading in some cases to major economic and social problems (Le Bissonnais et al., 2002; Martínez-Casanovas et al., 2005; Martínez-Casasnovas and Ramos, 2006).

Several studies have already shown the importance of relief (slope length and mean slope angle) both in the morphology of initiated erosive structures and in the volumes involved in soil erosion (Fox and Bryan, 2000; Hooke, 2006; Martínez-Casanovas et al., 2005; Montgomery and Dietrich, 1994; Quiquerez et al., 2008; Wischmeier and Smith, 1978). At metre scale, however, the erosion rate sometimes exhibits intra-plot

\footnotetext{
* Corresponding author.

E-mail address: amelie.quiquerez@u-bourgogne.fr (A. Quiquerez).
}

heterogeneity, which cannot be explained by mean slope angle and slope length of the plot (Brenot et al., 2008; Cerdan et al., 2010). As soil surface characteristics (soil cover, grain size, texture etc. ...) evolve spatially at the metre scale (Corbane et al., 2008), they too can influence hydric properties and erosion rates (Arnaez et al., 2007; Auzet et al., 1995, 2004, 2005). Agricultural practices may also affect soil variability and erosion rates. For example, tillage may induce some translocation and dispersion of the plough layer (Armand et al., 2009; Blavet et al., 2009; Govers et al., 1994, 1999; Poesen et al., 1994; Schumacher et al., 1999).

Intra-plot soil surface variability may be investigated from soil surface mapping (Mulder et al., 2011). Soil surface mapping often uses conventional soil surveys and laboratory analyses that are precise but time-consuming and extremely costly because of the number of measurements needed for soil surface mapping at a high spatial resolution (Mulder et al., 2011; Webster and Oliver, 1990). Conversely, other methods, using remote sensing techniques that have emerged over the last decades, are recognised as efficient methods to examine soil and landform relationships (Martin and Timmer, 2006; Mulder et al., 2011). Remote sensing techniques have successfully been employed for soil and terrain mapping at a global or catchment scale (Irvin et al., 1997; Martin and Timmer, 2006) and are expected to contribute to 
Digital Soil Mapping as an auxiliary data source (Lagacherie et al., 2007; McBratney et al., 2003) (see Mulder et al., 2011 for a review). Aerial or satellite imagery has also demonstrated their usefulness when studying the relationships between hydrological runoff, sediment erosion and soil surface characteristics (King et al., 2005), evaluating surface roughness (Baghdadi et al., 2002), or assessing intra-plot soil surface variability by estimating soil surface reflectance (Corbane, 2006; Corbane et al., 2008; Touriño Soto, 2005; Wassenaar et al., 2005).

Our approach combines sampling and remote sensing techniques at very high spatial resolution (VHSR), i.e. at a five centimetre spatial scale, to highlight fine spatial distribution of soil surface heterogeneities. This is an intermediate scale, between the regional scale of Digital Soil Mapping and limited local observations. The capacity and efficiency of remote sensing techniques to derive soil information have been proven at the regional scale, and are now applied in this study at plot scale. Our approach is applied in Burgundy vineyards where decennial erosion data are already available at a square metre scale (Brenot, 2007; Brenot et al., 2008), to assess the influence of soil surface heterogeneity and slope angle on erosion intensity in the Monthelie vineyards. In the following sections, the plot characteristics (soil surface topography and soil erosion data) and aerial image classification will be presented. The results of soil mapping will be combined with an intra-plot soil description allowing soil types to be defined by physical and chemical characteristics (stoniness, grain-size distribution, organic carbon, calcium carbonate, and total nitrogen content). Finally, soil surface topography, topsoil types and soil erosion data will be compared to assess their effects on erosion.

\section{Material and methods}

\subsection{The study area}

\subsubsection{Description of the study site and plot characteristics}

The study site is located on the hillslopes of the Monthelie vineyards, in the "Côte de Beaune" area (Burgundy, France) (Fig. 1A). The hillslopes, shaped by the Bressan rifting, form the eastern border of the Burgundy plateau. Vine-growing is attested on this fault-scarp relief since the Middle Ages (Garcia et al., 2010). The hillslopes are overlain by a silty-clayey calcaric cambisol (World reference base for soil resources, 2006) that develops on Jurassic marls, where white limestones contrast with the dark matrix of the soil (Figs. 1B, 2A). The plot is bordered upslope by the limestone plateau. Downslope, the plot is bounded by a rill collecting water
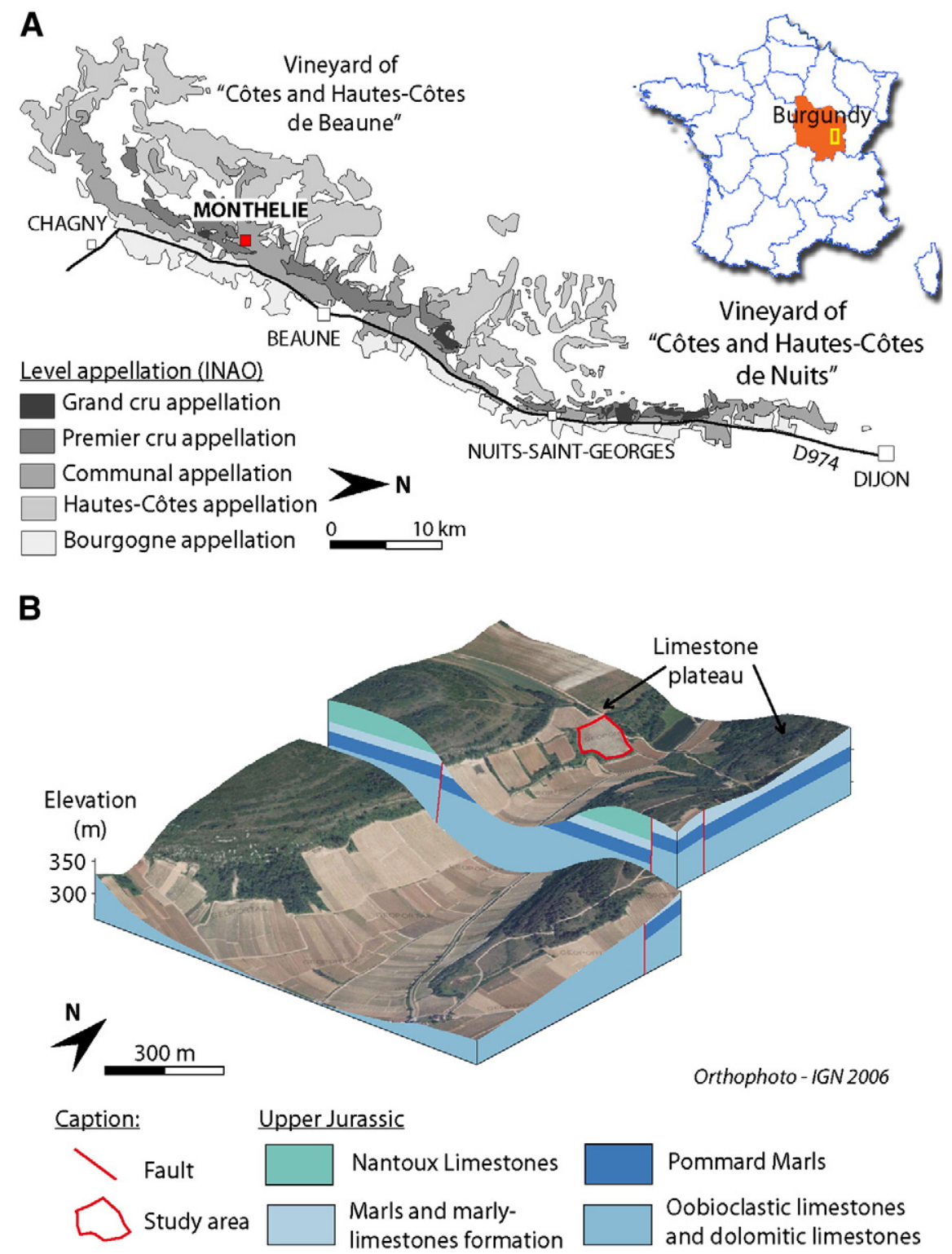

Fig. 1. (A) Location of the study area in the Monthelie vineyard, in the Côte de Beaune area (Burgundy, France) and (B) geology of the study area. 

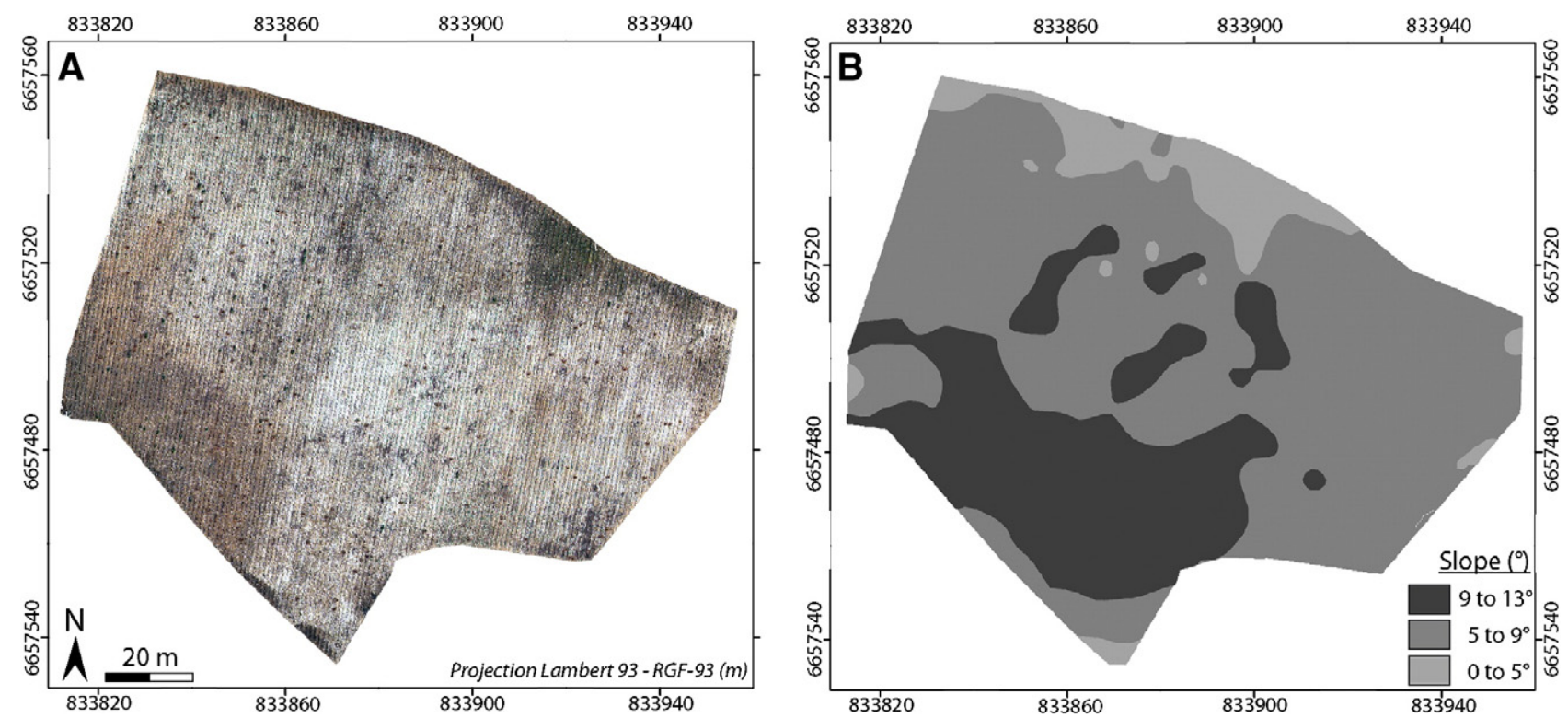

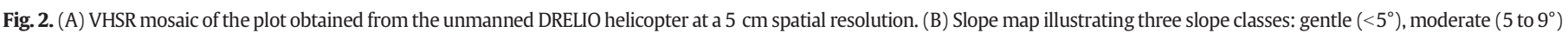
and steep slopes $\left(>9^{\circ}\right)$ et al. / Catena 116 (2014) 163-172

and sediment. Auger holes performed on the plot reveal that the soils are superficial and range in thickness from $30 \mathrm{~cm}$ upslope to $50 \mathrm{~cm}$ downslope. The landscape is characterised by a vine monoculture where the plot limits, i.e. paths and walls, form the only discontinuities on the hillslopes (Garrier, 1989). Vine stocks are planted $1 \mathrm{~m}$ apart, in rows $1 \mathrm{~m}$ apart; chemical weeding produces non-grassed rows; tillage in the inter-row is performed once or twice a year. The tillage is superficial and the inter-row roughness induced by the straddle-tractor traffic is minimal. These soil management practices and the slope-oriented vine rows are all factors which greatly increase erosion.

\subsubsection{Topographic data}

The studied plot ( $833.880 \mathrm{~m}, 6.657 .500 \mathrm{~m}$; Lambert 93 projection) is located on the northern part of the Combe Danay valley, on the upper part of the hillslope. The plot, corresponds to a total area of $9500 \mathrm{~m}^{2}$ (Fig. 2A). A digital elevation model (DEM) was obtained from a topographic survey with a laser theodolite (resolution of $15 \mathrm{~m}$, horizontal and vertical precision $<1 \mathrm{~cm}$ ). Slopes vary regularly from $1^{\circ}$ to $13^{\circ}$ from a planar to concave morphology (Fig. 2B). Three main slope classes were distinguished: the steepest slopes $\left(>9^{\circ}\right)$ are located in the south-western part of the plot (covering $24 \%$ of the plot), the central part is characterised by moderate slopes ( 5 to $9^{\circ}$, covering $67 \%$ of the plot), whilst gentle slopes (less than $5^{\circ}$ ) are found in the upper part of the plot (covering $9 \%$ of the plot). In this plot, vines were planted in 1982 with the rows in the steepest slope direction.

\subsubsection{Erosion data}

A 30-year average erosion map was performed at a square metre scale, from more than 9000 stock unearthing measurements (sum method, see Brenot, 2007; Brenot et al., 2008) (Fig. 3A). The principle of soil loss measurement is based on considering the unearthing of the stock located on the vine plants as a passive marker of soil surface vertical displacement since the year of plantation. Plantation practice, regimented by regional by-laws demands that the scion-graft union be located $1 \mathrm{~cm}$ above the soil surface when vines are planted (Galet, 2000), in order to prevent contact between the scion and the soil. During the vine's growth, the stock develops its own roots that are concentrated at the lower part of the stock whilst vine shoots develop from the scion (Brenot et al., 2008). The stock exposure is interpreted as reflecting the dynamics of soil aggradation/ablation, considering the scion-graft limit to be a marker of the initial topography. Plantation legislation imposes a density of 10,000 vines per hectare which allows the quantification of soil erosion at 1 metre resolution (Fig. 3B). Errors in unearthing measurements are related essentially to the vine plantation and to the downward shifting of the graft limit, which may underestimate the true soil lowering (Brenot et al., 2008). An error margin of $\pm 1 \mathrm{~cm}$ was added to the SUM to take into account the measurement error at the date of plantation (Brenot et al., 2008). The erosion class distribution is presented in Fig. 3C. Each pixel represents a measurement value, which is given in centimetre (Fig. 3D). The analysis of value distribution shows that all data are negative. This means that the entire plot is affected by erosion on a 30 year period. The mean erosion is about $-2.7 \mathrm{~cm}( \pm 1 \mathrm{~cm})$ with values ranging from $-1( \pm 1 \mathrm{~cm})$ to $-14 \mathrm{~cm}( \pm 1 \mathrm{~cm})$. Null erosion values (erosion value $\leq 1 \mathrm{~cm}$ ) represent $30 \%$ of total measurements. Forty per cent of the values of the dataset are associated with low erosion $(1 \mathrm{~cm}<$ erosion value $\leq 3 \mathrm{~cm})$. Moderate $(3 \mathrm{~cm}<$ erosion value $\leq 5 \mathrm{~cm}$ ) and high erosion values (erosion value $>5 \mathrm{~cm}$ ) are obtained for about $19 \%$ and $9 \%$ of the measurements, respectively.

\subsection{Topsoil mapping from very high spatial resolution (VHSR) image processing}

The VHSR images were acquired in April 2010 by the unmanned helicopter DRELIO (Université Lyon 1-Université de Bretagne Occidentale, France) (Delacourt et al., 2009) at $5 \mathrm{~cm}$ spatial resolution (Fig. 2A). The helicopter is equipped with a reflex digital camera (Nikon D200, 10 MegaPixels) with a $35 \mathrm{~mm}$ equivalent focal length (chip size $24 \mathrm{~mm}$ ), an automatic piloting system and an onboard GPS giving the geographic position during the flight. Images were acquired at a constant $70 \mathrm{~m}$ flying altitude to avoid geometrical deformation and during early spring, to avoid leaf and plant cover. The camera was set to "manual" with a velocity acquisition of $1 / 4000 \mathrm{~s}$ and a constant opening (f/4.5). The images were saved in 12-bit raw mode to preserve the maximum of radiance information. The duration of a flight was less than $30 \mathrm{~min}$ and the flight took place near solar midday. Illumination conditions were thus nearly constant and no substantial radiance differences have been observed from one image to the next.

Image pre-processing consists in the construction of a mosaic from 30 selected images. The images were first georeferenced using control points from a differential GPS, and then pseudo-orthorectified. The artefacts obstructing soil information (roads, agricultural paths, vinestocks and their shadows) were masked by segmentation before image 

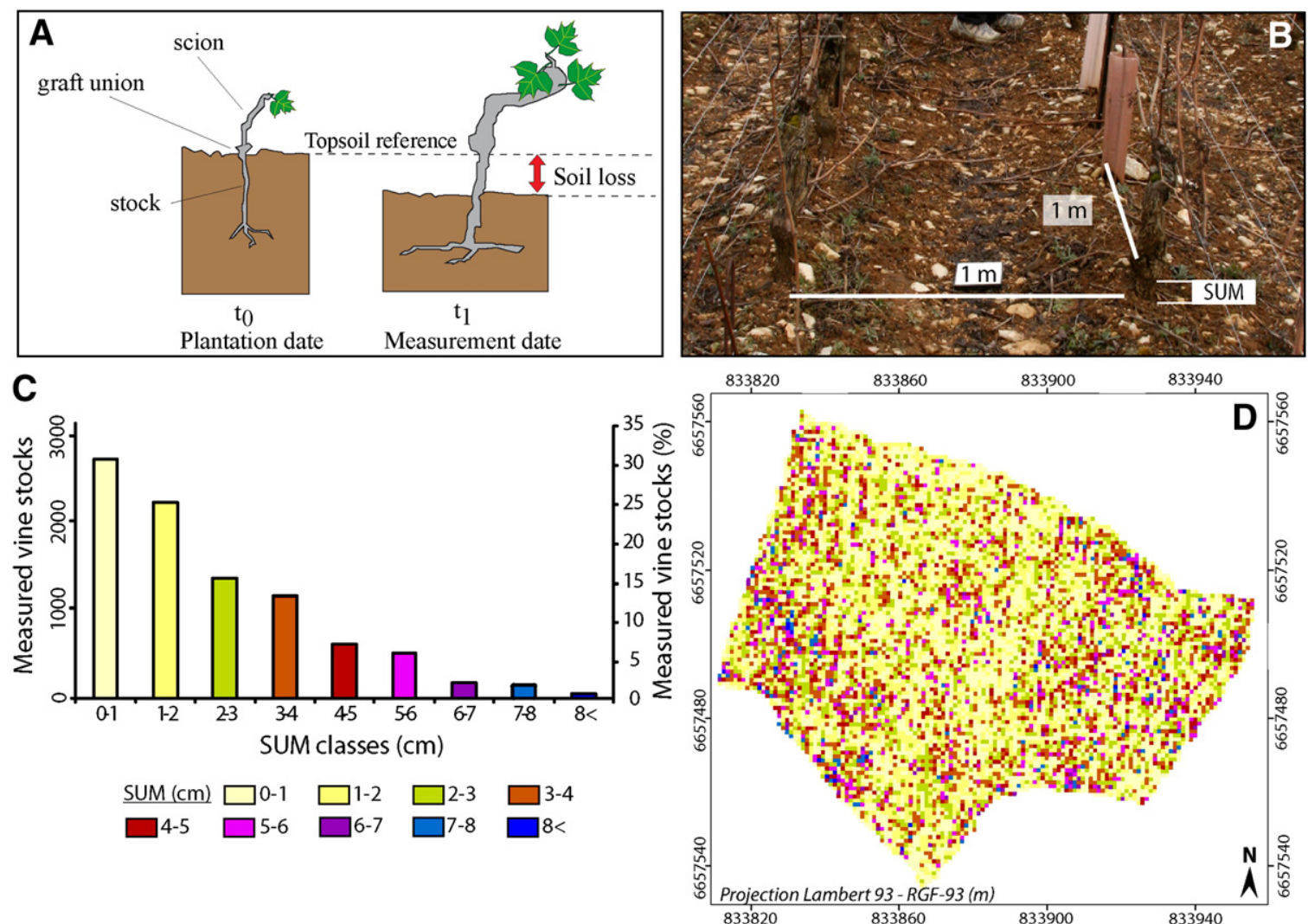

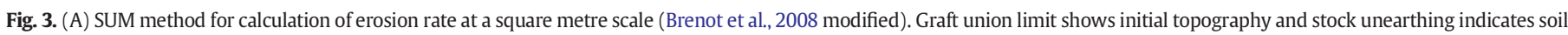

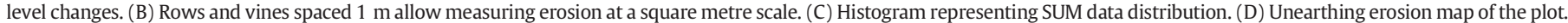
Yellow indicates null to very low erosion $(\leq 1 \mathrm{~cm})$ whereas blue indicates very high erosion $(\geq 8 \mathrm{~cm})$.

analysis. Images of the soil surface were classified using an unsupervised ISODATA method (i.e. "Iterative Self Organizing Data Analysis Technique") (Hall and Khanna, 1977) that is frequently applied to map landform or to examine soil-landform relationships in various land uses (Adediran et al., 2004; Burrough et al., 2000; Irvin et al., 1997). The algorithm uses an iterative statistical approach to cluster pixels into homogeneous areas of similar characteristics (i.e. into classes), without any a priori knowledge of their spatial distribution. The user defines a minimum and a maximum number of possible classes. The pixels are affected to a given class using a minimum Euclidian distance technique by an iterative computation. The result is independent of the interpretation of the image by the user.

In the study site, we merely set between two and eight the number of soil classes in the plots. This range of values implies that more than two different radiance values should be identified, which is justified by the presence of white limestones and dark soil matrix. This also signifies that fewer than eight soil classes may be defined. This value was never reached after iterative processing, validating a posteriori this choice. Finally, to allow the comparison between soil surface distribution and erosion measurements, a low-pass filter (Gaussian blurring) on a $5 * 5$ kernel grid $(25 \mathrm{~cm} * 25 \mathrm{~cm})$ has been applied on the classified images to smooth any local superficial heterogeneity present at a scale less than $1 \mathrm{~m}^{2}$. The obtained images have then been resampled at a $1-\mathrm{m}$ resolution using a median filter.

\subsection{Topsoil characteristics from laboratory analyses}

Local observations and analyses were performed to describe the soil surface states defined by image processing (Fig. 4). Soil sampling sites were selected within the spatial distribution of the classes described above. For each class, five random samples were collected in order to characterise the physical and chemical properties of the soil surface state classes defined by image processing. For each sample, we performed field observations and laboratory analyses to define stoniness and grain-size distribution according to the techniques of the French Association for Normalisation (AFNOR). These samples were used to quantify the total organic carbon, calcium carbonate, and total nitrogen contents. All results are presented in Fig. 6 and in Table 1.

\subsubsection{Stoniness and grain-size distribution analysis}

Samples were collected in the $0-10 \mathrm{~cm}$ soil layer in the inter-row over a $0.25 \mathrm{~m}^{2}$ surface to determine soil stoniness and grain-size distribution. Stoniness ( $>2 \mathrm{~mm}$ fraction) is obtained by weighing and sieving on undispersed material using dryness agitation. The moist soil residue was weighed and oven-dried for $24 \mathrm{~h}\left(40{ }^{\circ} \mathrm{C}\right)$ to determine the dry weight. A grain-size distribution was obtained using sieve sizes for the $250 \mu \mathrm{m}-2 \mathrm{~mm}$ fraction (coarse sand), the $63 \mu \mathrm{m}-250 \mu \mathrm{m}$ (medium and fine sand), and the fraction lower than $63 \mu \mathrm{m}$ (silts and clays) (French norm NF P18-560).

\subsubsection{Total carbon, calcium carbonate, nitrogen and organic carbon contents}

The total calcium carbonate content was estimated using the Bernard calcimeter (international norm NF ISO 10693). Total carbon and nitrogen contents were determined by pyrolysis $\left(980{ }^{\circ} \mathrm{C}\right)$ under oxidising conditions and dosage of $\mathrm{CO}_{2}$ and $\mathrm{N}_{2}$ released by gas chromatography, following the standard norm NF ISO 10694. The organic 


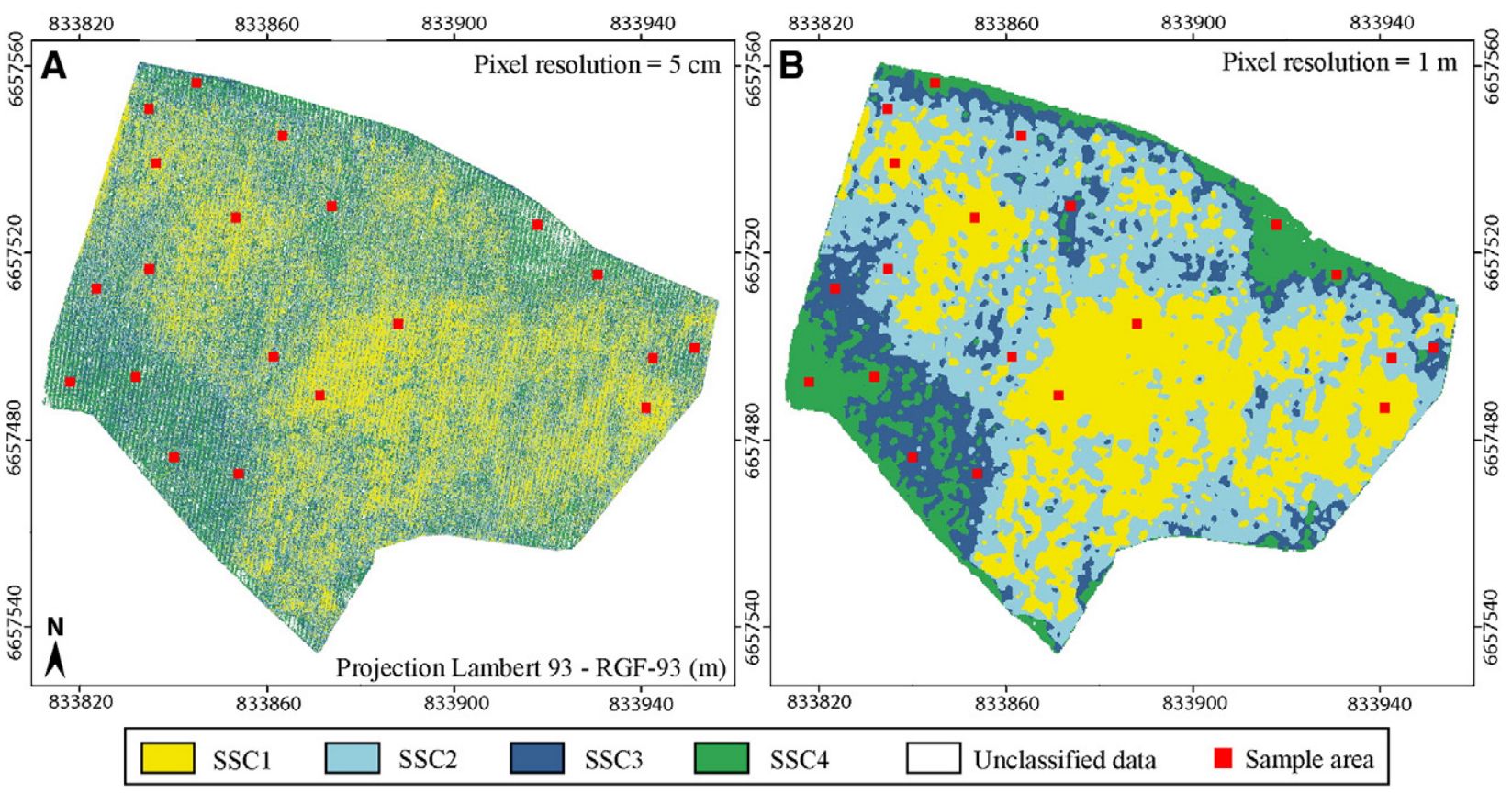

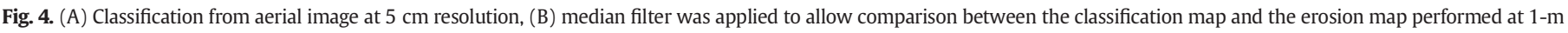
resolution. On each map, four classes have been determined on the basis on radiance values. The soil sampling locations are defined by the spatial distribution of these classes.

carbon content was obtained from this value by correcting from the total carbonate carbon (NF ISO 10963).

\section{Results}

\subsection{Soil surface classification from VHSR}

Fig. 4A and B illustrates respectively the soil surface classification at $5 \mathrm{~cm}$ and $1 \mathrm{~m}$ resolution. The image classification accentuates soil radiance differences detectable in the natural mosaic between bright surfaces covered by stones and dark surface dominated by the siltyclayey matrix (Fig. 2A).

Four classes of radiance were distinguished and interpreted as four soil surface state classes (SSC), defining specific areas within the studied plots (Figs. 4 and 5). The SSC1 (35\% of the total surface) and the SSC2 (38\% of the surface) are essentially located in the central part of the plot and are defined by bright soil surface states with high radiance values. The SSC 3 ( $16 \%$ of the surface) and SSC 4 classes ( $11 \%$ of the surface) are observed in the upper eastern part and in the lower part of the plot. They correspond to darker soil surfaces, defined by lower radiance values.

\subsection{Soil surface characteristics}

Physico-chemical characteristics of soil surface classes (SSCs) are presented in Table 1. Total carbonate content ranging between 128\%。 and $144 \%$, was not a discriminating factor between SSCs. Organic carbon and nitrogen contents varied from $3.5 \%$ to $4.7 \%$, and $0.20 \%$ to $0.30 \%$ respectively. SSC3 and SSC4 displayed a high variability in organic carbon and nitrogen contents, whilst the range of variations remained limited for SSC1 and SSC2. Stoniness was high and decreased from SSC1 (77\%) to SSC4 (56\%). This trend was anti-correlated to the sand and fine silty-clayey fractions. SSCs displayed low intra-class variability in the stoniness, but also in the silty-clayey fraction, with the exception of SSC3.

SSC1 showed a very high stoniness (77\%), a very low silty-clayey fraction (18\%), and a total organic carbon content of $4.1 \%$. The range of variation was limited in both the physical and chemical properties. SSC2 was similar to SSC1 but displayed a lower stoniness (70\%), a higher silty-clayey fraction (24\%), a higher organic carbon and total nitrogen contents ( $4.7 \%$ and $0.30 \%$ respectively). SSC3 showed the highest values of calcium carbonate (144\%), displaying moderate stoniness, high silty-clayey fraction, lower organic carbon and nitrogen contents, and a higher $\mathrm{C} / \mathrm{N}$ ratio (26.2), in comparison to those of SSC1 and SSC2. SSC4 was similar to SSC3 but contains lower carbonate content (131\%), higher organic carbon content $(4.1 \%)$ and a lower variability than that of SSC3.

Box plot (Fig. 6) highlighted some differences between SSCs in stoniness, silty-clayey fraction, organic carbon and total nitrogen contents. Therefore, these analyses showed that each soil surface class identified from image processing was representative of soil surface characteristics defined by specific chemical and physical properties.

This new approach makes it possible to assess the spatial relation between soil surface characteristics (Fig. 4), slopes (Fig. 2B) and erosion

Table 1

Mean and standard deviation (between brackets) values for each SSC.

\begin{tabular}{|c|c|c|c|c|c|c|c|}
\hline & Stoniness & Sands & Silts and clays & Total carbonate content & Organic carbon content & Total nitrogen content & $\mathrm{C} / \mathrm{N}$ ratio \\
\hline & $\%$ & $\%$ & $\%$ & $\%$ & $\%$ & $\%$ & \\
\hline SSC1 & $77(5)$ & $5(1)$ & $18(4)$ & $128(17)$ & $4.1(0.3)$ & $0.25(0.02)$ & $21.3(2.5)$ \\
\hline SSC2 & $70(5)$ & $6(3)$ & $24(3)$ & $129(30)$ & $4.7(0.4)$ & $0.30(0.02)$ & $22.0(2.8)$ \\
\hline SSC3 & $58(10)$ & $7(3)$ & $34(9)$ & $144(62)$ & $3.5(1.1)$ & $0.20(0.07)$ & $26.2(5.6)$ \\
\hline SSC4 & $56(7)$ & $8(1)$ & $35(7)$ & $131(35)$ & $4.1(0.6)$ & $0.27(0.07)$ & $22.8(6.4)$ \\
\hline
\end{tabular}



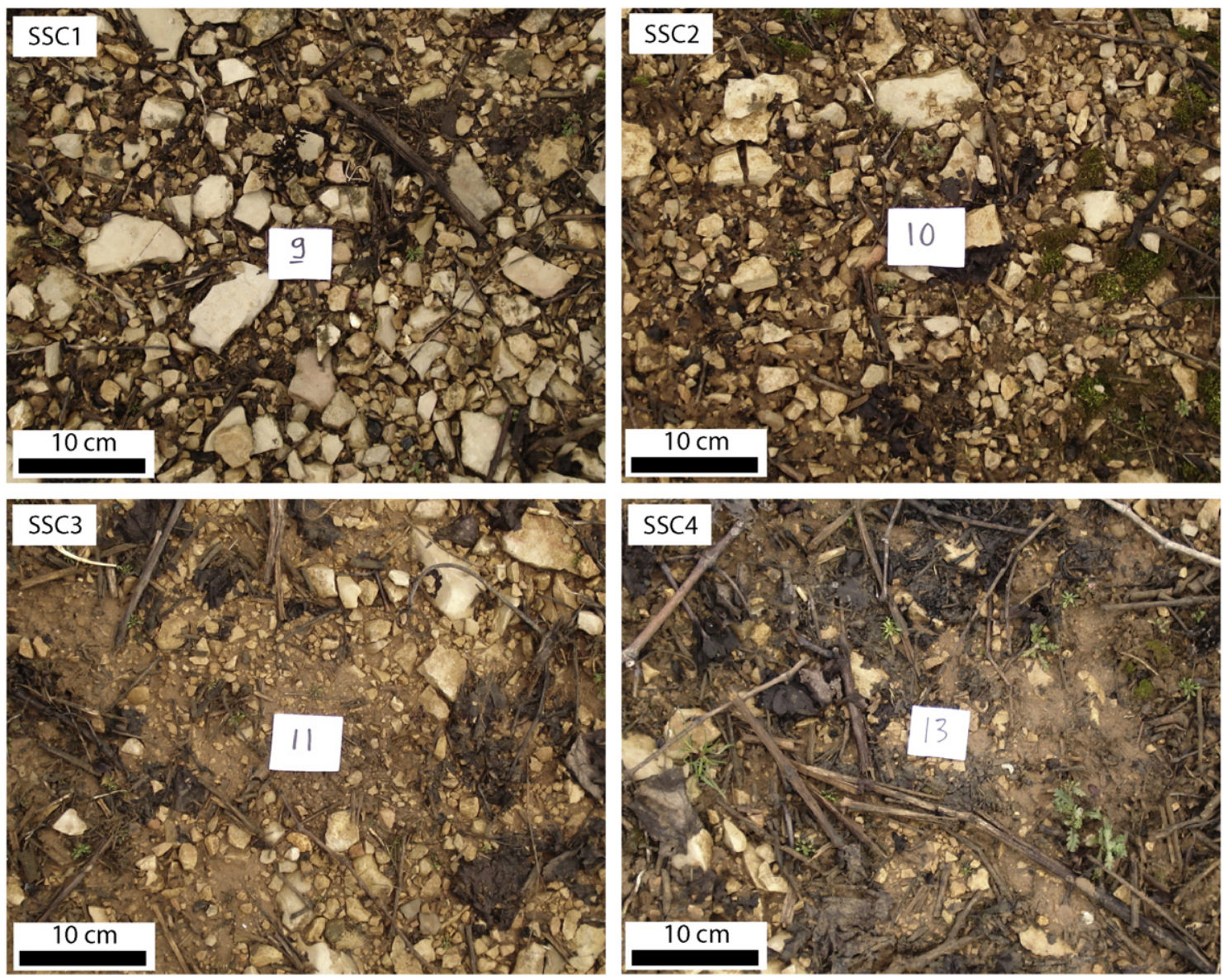

Fig. 5. Photographs of the four SSC recognised by image analyses. Stoniness decreases from SSC1 to SSC4.

(Fig. 3). All the data were collected in a GIS database. The comparisons between slope, soil and erosion maps have been synthesised in Figs. 7 and 8 .

\subsection{Soil surface characteristics, slope and erosion}

\subsubsection{Slope and erosion}

At the plot scale, spatial and statistical analyses of the slope and erosion data (Figs. 2B and 3D) showed that the erosion values were higher in the south-western part of the plot, located on steep slopes (mean value of $2.8 \mathrm{~cm} \pm 1.7$ ) than in the upper part, located on gentle slopes (mean value of $2.2 \mathrm{~cm} \pm 1.5)(\mathrm{p}<0.0001$ Mann-Whitney test).

Fig. 7A illustrates the distribution of erosion for each slope class. The surfaces covering the same slope values were not identical. Therefore, the erosion data distribution had been normalised over the surface according the moderate slope class that is the most representative, in order to evaluate the importance of the slope effect on erosion (Fig. 7B). Null to very low erosion values ( $\mathrm{sum} \leq 1 \mathrm{~cm}$ ) were found dominantly in the gentler slopes (slopes $<5^{\circ}$ ) whilst low erosion values $(1<\mathrm{sUM} \leq 3 \mathrm{~cm})$ are almost slope-independent. Conversely, moderate to high unearthing values ( $\mathrm{SUM} \geq 4 \mathrm{~cm}$ ) are dominantly found on moderate and steep slopes. More than $85 \%$ very high values (SUM $\geq 8 \mathrm{~cm}$ ) are located on moderate and steep slopes ( slopes $>9^{\circ}$ ).

\subsubsection{Spatial relation between SSC and erosion}

The soil surface distribution (Fig. 4) has been compared to the erosion map (Fig. 3) to study the spatial relationships between the intensity and localisation of erosion and the topsoil characteristics. Table 2 showed that SSC1 and SSC2, that contains a high stoniness, are associated to lower mean values (mean SUM of $2.5 \mathrm{~cm}$ and $2.6 \mathrm{~cm}$ respectively) than those for SSC3 and SSC4 $(2.9 \mathrm{~cm}$ and $3 \mathrm{~cm}$ respectively)
( $\mathrm{p}<0.0001$, Mann-Whitney test). Fig. 7C presented the distribution of SSC classes for each sum class. Values have been normalised over the surface covered by each SSC to allow comparison between data (Fig. 7D). Very low values ( $\mathrm{Sum} \leq 1 \mathrm{~cm}$ ) are more commonly found in SSC1 and SSC2 (stony soil surface) located in the central part of the plot, than in SSC3 and SSC4 (more silty-clayey soils). Low erosion classes $(1<$ sum $\leq 3 \mathrm{~cm})$, which are slope-independent, are also uniformly distributed across the plot, independently to the SSCs (approximately $40 \%$ for each SSC). Fig. 8 showed that very high erosion values (SUM $>5 \mathrm{~cm}$ ) were preferentially associated with low stoniness surface states encountered in SSC3, SSC4 located in the south-western part and on the northern border of the plot. In this plot, the pattern of erosion seemed to be related to the spatial distribution of soil surface states, and specifically to the stoniness. Fig. 9 shows that low to moderate erosion (sum $\leq 5 \mathrm{~cm}$ ) are associated to high radiance values induced by a white stone surface cover. Conversely, in the south-western part of the plot, soils that are rich in fine fraction are more easily eroded, and display a lower radiance (Fig. 9 for sum $\geq 8 \mathrm{~cm}$ ).

\section{Discussion}

In vineyard contexts, erosion is controlled by interactions and feedback between natural and anthropogenic processes (Boardman and Poesen, 2006). Several studies have demonstrated the importance of water-induced erosion in contributing to sediment transfer at the hillslope scale (Hooke, 2006; Martínez-Casanovas et al., 2005; Quiquerez et al., 2008). Other studies have highlighted the role of anthropogenic factors, i.e. tillage and agricultural management, on the spatial distribution of erosion (Armand et al., 2009; Blavet et al., 2009; Chartin et al., 2011; Kosmas et al., 1997; Paroissien et al., 2010; Schumacher et al., 1999). Others have shown that sediment dynamics on hillslope may 

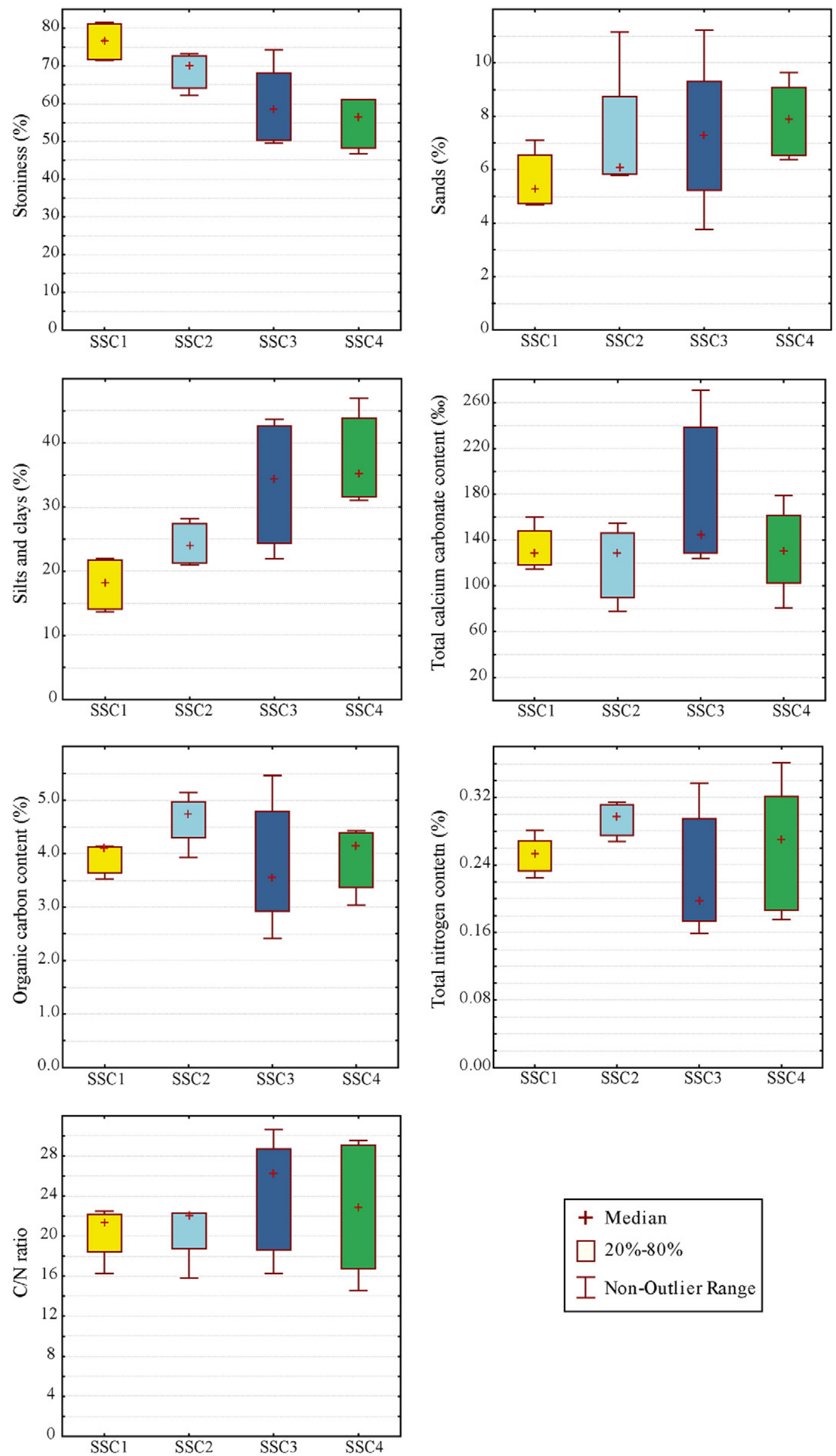

Fig. 6. Stoniness, sand and silty-clayey fractions, organic matter content, total nitrogen content and C/N content for each of the SSC classes defined by image analysis.e 

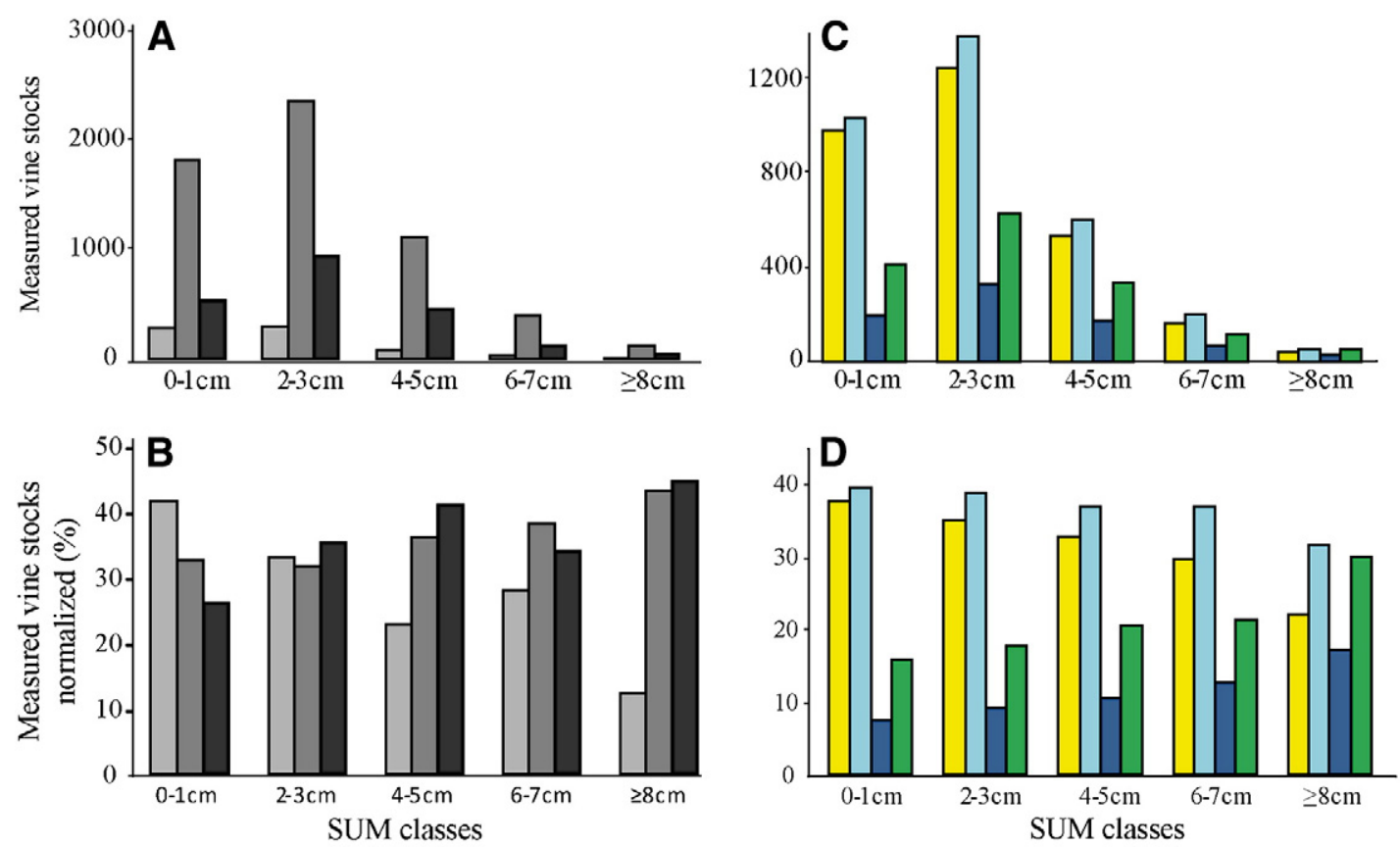

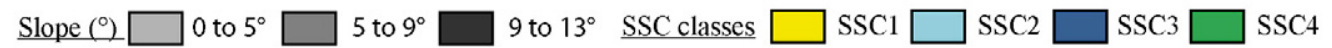

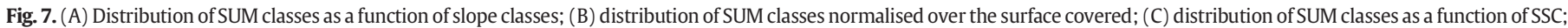
(D) distribution of SUM classes normalised over the surface covered.

also be related to former plot boundaries in agricultural landscapes at catchment scale (Hooke, 2006; Jordan et al., 2005; Szilassi et al., 2006).

In the Monthelie vineyard plot, comparisons between soil surface distribution and erosion maps show that low and moderate erosion areas are preferentially located in the central part of the plot, where stony SSC1 and SSC2 prevail. Conversely, high erosion values are located in the south-western part of the plot, which is less stony, and where there is a break in slope. We suggest that these SSCs reflect the action of hydric erosion, present-day management practices and, possibly a land use evolution over time.

Our work shows that the pattern of erosion of this plot is inversely correlated to the spatial distribution of the stone percentage at the metre scale. The paved soil surface, rich in stones, protects from the splash effect, delays runoff processes and thus reduces soil erosion (Martínez-Zavala and Jordán, 2008; Martinez-Zavala et al., 2010; Poesen and Lavee, 1994; Puigdefabregas et al., 1996). In the central part of the plot, where erosion is limited, the high stoniness and the superficial pavement observed in SSC1 and SSC2 may have resulted from the selective and progressive removal of fine particles by overland flows during repeated high intensity rainfall events (Poesen and Lavee, 1994; Poesen et al., 1990). Indeed, in Burgundian vineyards, intense rainfall events are known to mobilise and transport particles. Conversely, repeated tillage operations may cause the enrichment of the rock-fragment fraction in the topsoil (Follain et al., 2012; Govers et al.,

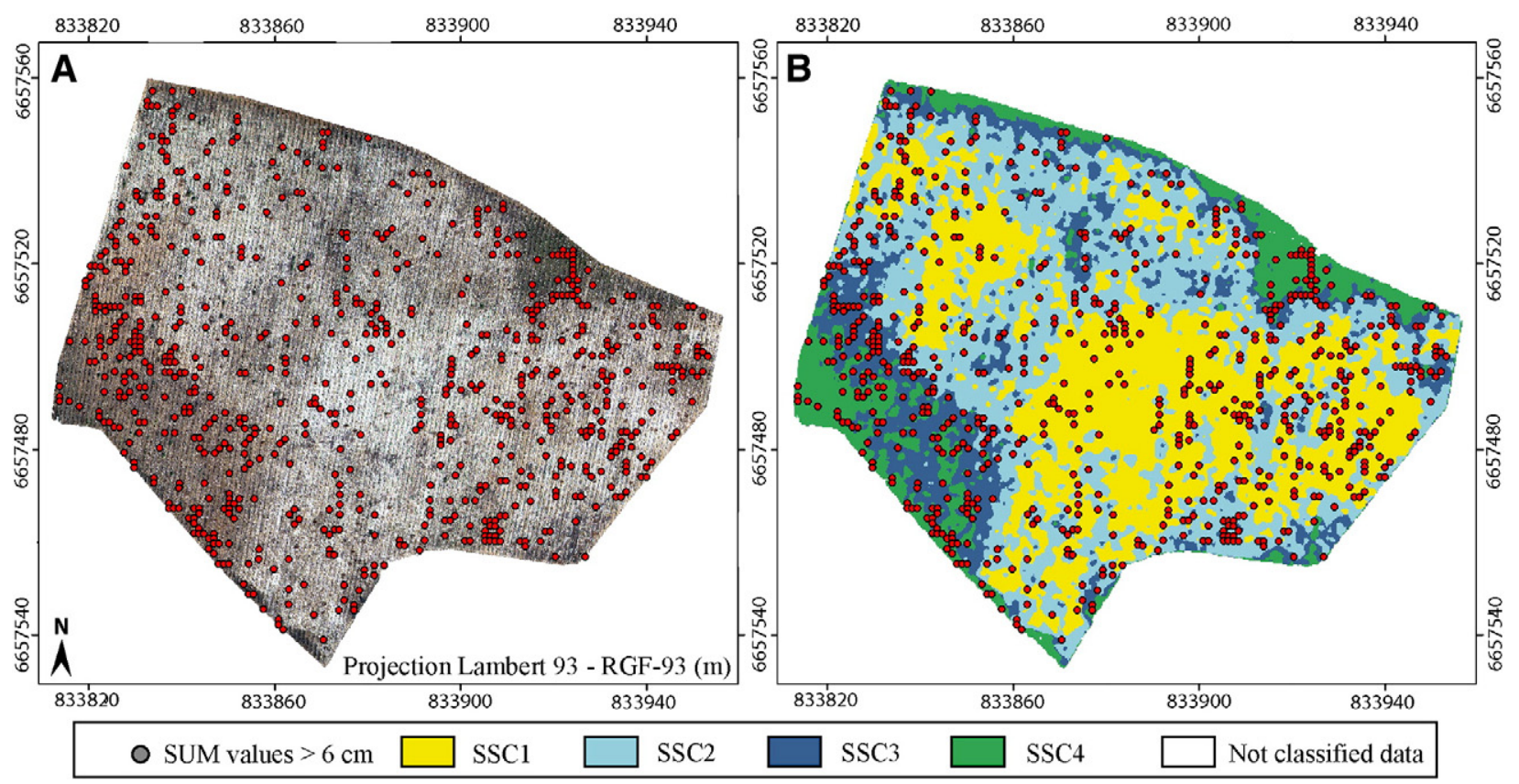

Fig. 8. Spatial distribution of very high erosion values ( $\mathrm{sum} \geq 6 \mathrm{~cm}$ ) (A) over the VHSR aerial image, (B) over the topsoil classification map. 
Table 2

Mean SUM and standard deviation values for each SSCs.

\begin{tabular}{lll}
\hline & \multicolumn{2}{l}{ SUM $(\mathrm{cm})$} \\
\cline { 2 - 3 } & Mean & Standard deviation \\
\hline SSC1 & 2.5 & 1.7 \\
SSC2 & 2.6 & 1.7 \\
SSC3 & 2.9 & 1.8 \\
SSC4 & 3.0 & 1.9 \\
\hline
\end{tabular}

1994, 1999; Poesen et al., 1997). Here, SSC1 can hardly be attributed to water erosion alone, since slope gradient is minimal in the upper part of the plot, suggesting a medium to long-term combined water and tillagecontrolled erosion. Identical surface soil degradation in upper slope positions has been observed in various parts of the European Mediterranean belt in cultivated areas (Cerdan et al., 2010; Poesen and Lavee, 1994; Schumacher et al., 1999). This degradation is however complete, since the observed pavement suggests that SSC1 will evolve no further, unless superficial tillage is performed once or twice a year.

Our work also shows that there is a global control of the topography over the localisation and intensity of the erosion operating over the plot. In the south-western part of the plot, where a break in slope is observable, the erosion rates are high and the SSCs are characterised by low stoniness. Auger holes performed in the steep slope area show that no rock fragments have been found deeper in the soil profile. The soils remain superficial since they range in thickness from $30 \mathrm{~cm}$ upslope to $50 \mathrm{~cm}$ downslope. The steep slope suggests water-dominated erosion in this area, illustrating the superficial dynamics currently operating on these hillslopes. Fine-grained particles are easily mobilised during each high intensity rainfall event. They are gradually transferred downslope and may be temporarily stored, even on these steep slopes. The evolution from upslope topsoils that are depleted in fine particles to enriched downslope soils may reflect these short-term hillslope dynamics. In the medium to long term, such soil erosion can lead to a modification of these SSCs, in quantitative and qualitative ways, since upslope fine particles are exported out of the plot. Evidence of such hillslope dynamics can be illustrated by the soil characteristics in the SSC2 and SSC3 classes, which present intermediate values between those of SSC1 and SSC4, in terms of stoniness, sand and silty-clayey fractions. Fig. $4 \mathrm{~B}$ shows that the soil surface grades more or less gradually from one soil class to another.

If sediment dynamics may contribute to the enrichment of soils in fine particles in the south-western part of the plot, the examination of a 1953 aerial photograph (Fig. 10) suggests that the current pattern of soil distribution may have been also influenced by a land-use change in the medium term. The 1953 aerial photograph shows that the upslope part of the plot was occupied by a wasteland, whilst the downslope area was covered by forest. The limit between the wasteland and the forest matches the break in slope, between the moderate and

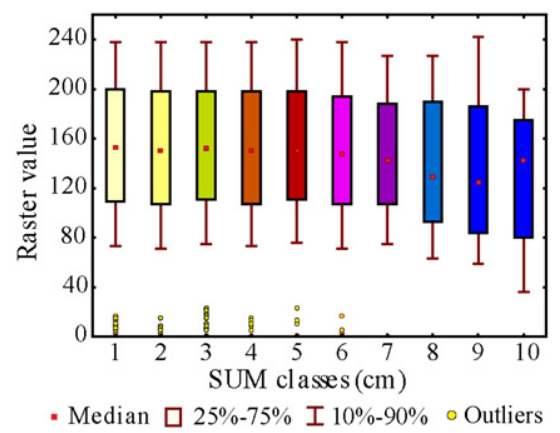

Fig. 9. Distribution of SUM classes as a function of raster value. Very high erosion values ( $\mathrm{SUM} \geq 8 \mathrm{~cm}$ ) are related to lower raster values than low to moderate erosion values ( $\mathrm{SUM} \leq 5 \mathrm{~cm})$

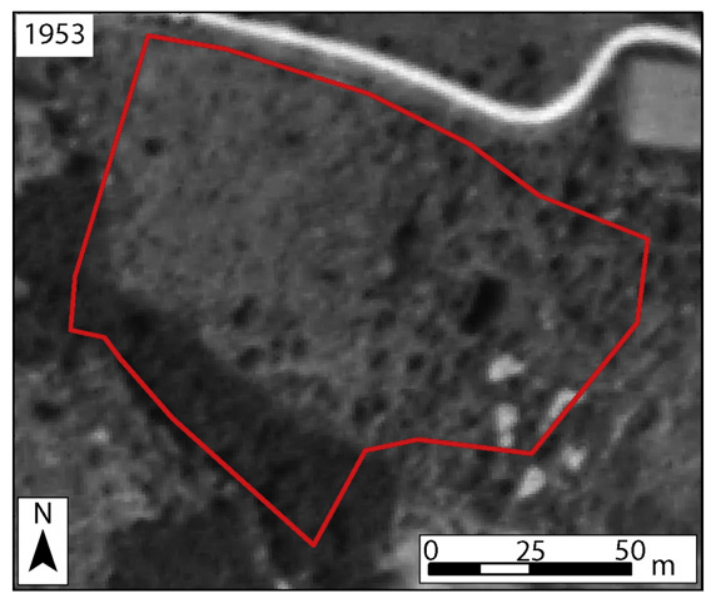

Fig. 10. The 1953 aerial photography highlights the presence of a forest in the downslope part of the plot whereas the upslope part was occupied by a wasteland. The limit matches the break in slope, between the moderate and steep slope areas. 1

steep slope areas (Fig. 10). Therefore, it is possible that the forest cover before 1982 had played a role in the location and preservation of the enriched soils observed in the southern-part of the slope.

Finally, our study shows that analysis of VHSR aerial images is a nonintrusive, quickly-performed method that it makes possible to generate full, detailed views of the soil surface. The classification map created from VHSR aerial images can be considered as an efficient qualitative indicator of soil surface distribution if it is combined with on-site quantitative soil analysis to define soil surface characteristics. Our combined observations based on very high spatial resolution suggest that the current pattern of soil distribution and erosion reflect the effects of geomorphological processes but also of present-day tillage and probably of a land-use change in the medium term.

These high resolution observations provide new insights to explain intra-plot spatial variability by integrating spatial, temporal, local and continuous data. Such maps can be helpful to assess the role of soil distribution in soil degradation processes and forecasting. Such an approach could be also very useful to optimise management practices for precision viticulture.

\section{Conclusions}

This paper presents a simple, highly efficient approach to map soil surface heterogeneities at a five centimetre resolution in Burgundy vineyards. This approach relies on the combination between very high resolution aerial data at the plot/hillslope scale and local soil observations. VHSR aerial image processing allows precise mapping of the spatial distribution of soil surfaces; soil sampling defines soil typology by physical and chemical characteristics. The combination of on-site soil data and VHSR aerial photos permits production of continuous and accurate spatial distribution maps at a very fine spatial resolution. By allowing the visualisation of soil distribution at very high spatial resolution, this approach offers new insights and possibilities for documenting soil patterns and for exploring and predicting soil evolution through space and time on hillslopes, which can be important for agricultural planning.

\section{Acknowledgements}

This work was financially supported by the Burgundy regional council (CRB) and the inter-professional bureau of Burgundy vines (BIVB). Thanks to $C$. Chateau-Smith for proof-reading the English text. The detailed comments of the anonymous reviewers were greatly appreciated and helped to improve the manuscript. 


\section{References}

Adediran, A., Parchartidis, I., Poscolieri, M., Pavlopoulos, K., 2004. Computer-assisted discrimination of morphological units on north-central Crete (Greece) by applying multivariate statistics to local relief gradients. Geomorphology 58, 357-370.

Armand, R., Bockstaller, C., Auzet, A.-V., Van Dijk, P., 2009. Runoff generation related to intra-field soil surface characteristics variability, application to conservation tillage context. Soil Tillage Res. 102, 27-37.

Arnaez, J., Lasanta, T., Ruiz-Flaño, P., Ortigosa, L., 2007. Factors affecting runoff and erosion under simulated rainfall in Mediterranean vineyards. Soil Tillage Res. 93, 324-334.

Auzet, A.V., Boiffin, J., Ludwig, B., 1995. Concentrated flow erosion in cultivated catchments: influence of soil surface state. Earth Surf. Process. Landf. 20, 759-767.

Auzet, A.V., Poesen, J., Valentin, C., 2004. Soil surface characteristics: dynamics and impact on soil erosion. Earth Surf. Process. Landf. 9, 1063-1064.

Auzet, A.V., van Dijk, P., Kirkby, M.J., 2005. Surface characterisation for soil erosion forecasting. Catena 62, 77-78.

Baghdadi, N., Gaultier, S., King, C., 2002. Retrieving surface roughness and soil moisture from synthetic aperture radar (SAR) data using neural networks. Can. J. Remote. Sens. 28, 701-711.

Blavet, D., De Noni, G., Le Bissonnais, Y., Leonard, M., Maillo, L., Laurent, J.Y., Asseline, J., Leprun, J.C., Arshad, M.A., Roose, E., 2009. Effect of land use and management on the early stages of soil water erosion in French Mediterranean vineyards. Soil Tillage Res. 106, 124-136.

Boardman, J., Poesen, J., 2006. Soil erosion in Europe: major processes, causes and consequences. In: Boardman, J., Poesen, J. (Eds.), Soil Erosion in Europe. Wiley, Chichester, pp. 479-487.

Brenot, J., 2007. Quantification de la dynamique sédimentaire en contexte anthropisé. Thèse de doctorat. Université de Bourgogne, Centre des Sciences de la Terre (262 pp.).

Brenot, J., Quiquerez, A., Petit, C., Garcia, J.P., 2008. Erosion rates and sediment budgets in vineyards at 1-m resolution based on stock unearthing (Burgundy, France). Geomorphology 100, 345-355.

Burrough, P.A., van Gaans, P.F.M., MacMillan, R.A., 2000. High-resolution landform classification using fuzzy k-means. Fuzzy Sets Syst. 113, 37-52.

Cerdan, O., Govers, G., Le Bissonnais, Y., Van Oost, K., Poesen, J., Saby, N., Gobin, A., Vacca, A. Quinton, J., Auerswald, K., Klik, A., Kwaad, F.J.P.M., Raclot, D., Ionita, I., Rejman, J., Rousseva, S., Muxart, T., Roxo, M.J., Dostal, T., 2010. Rates and spatial variations of soil erosion in Europe: a study based on erosion plot data. Geomorphology 122, 167-177.

Chartin, C., Bourennane, H., Salvador-Blanes, S., Hinschberger, F., Macaire, J.-J., 2011. Classification and mapping of anthropogenic landforms on cultivated hillslopes using DEMs and soil thickness data-example from the SW Parisian Basin, France. Geomorphology 135, 8-20.

Corbane, C., 2006. Reconnaissance des états de surface en milieu cultivé méditerranéen par télédétection optique à très haute résolution spatiale. Université de Montpellier II (252 pp.).

Corbane, C., Raclot, D., Jacob, F., Albergel, J., Andrieux, P., 2008. Remote sensing of soil surface characteristics from a multiscale classification approach. Catena 75, 308-318.

Delacourt, C., Allemand, P., Jaud, M., Grandjean, P., Deschamps, A., Ammann, J., Cuq, V., Suanez, S., 2009. DRELIO: an unmanned helicopter for imaging coastal areas. J. Coast. Res. Spec. Issue 56, 1489-1493.

Follain, S., Ciampilini, R., Coulouma, G., Crabit, A., Garnier, F., 2012. The effects of redistribution processes on rock fragment variability within a vineyard topsoil in Mediterranean France. Geomorphology 175-176, 45-53.

Fox, D.M., Bryan, R.B., 2000. The relationship of soil loss by interrill erosion to slope gradient. CATENA 38, 211-222.

Galet, P., 2000. Precis de viticulture, 7ème éd.

Garcia, J.-P., Chevrier, S., Dufraisse, A., Foucher, M., Steinmann, R., 2010. Le vignoble galloromain de Gevrey-Chambertin "Au-dessus-de Bergis», Côte-d'Or (Ier-Ile s. ap. J.-C.): modes de plantation et de conduite de vignes antiques en Bourgogne. Revue archéologique de l'Est 59, 505-537.

Garrier, G., 1989. Le phylloxéra. Une guerre de trente ans, 1870-1900. Albin Michel, Paris.

Govers, G., Vandaele, K., Desmet, P., Poesen, J., Bunte, K., 1994. The role of tillage in soil redistribution on hillslopes. Eur. J. Soil Sci. 45, 469-478.

Govers, G., Lobb, D.A., Quine, T.A., 1999. Tillage erosion and translocation: emergence of a new paradigm in soil erosion research., 51 167-174.

Hall, J., Khanna, D., 1977. Statistical Methods for Digital Computers. Wiley, New-York.

Hooke, J.M., 2006. Human impacts on fluvial systems in the Mediterranean region. Geomorphology 79, 311-335.

Irvin, B., Ventura, S., Slater, B., 1997. Fuzzy and isodata classification of landform elements from digital terrain data in Pleasant Valley, Wisconsin. Geoderma 77, 137-154.

Jordan, G., van Rompaey, A., Szilassi, P., Csillag, G., Mannaerts, C., Woldai, T., 2005. Historical land use changes and their impact on sediment fluxes in the Balaton basin (Hungary). Agric. Ecosyst. Environ. 108, 119-133.

King, C., Baghdadi, N., Lecomte, V., Cerdan, O., 2005. The application of remote sensing data to monitoring and modelling of soil erosion. Catena 62, 79-93.
Kosmas, C., Danalatos, N., Cammeraat, L.H., Chabart, M., Diamantopoulos, J., Farand, R., Gutierrez, L., Jacob, A., Marques, H., Martinez-Fernandez, J., Mizara, A. Moustakas, N., Nicolau, J.M., Oliveros, C., Pinna, G., Puddu, R., Puigdefabregas, J. Roxo, M., Simao, A., Stamou, G., Tomasi, N., Usai, D., Vacca, A., 1997. The effect of land use on runoff and soil erosion rates under Mediterranean conditions. Catena 29, 45-59.

Krause, A.K., Franks, S.W., Kalma, J.D., Loughran, R.J., Rowan, J.S., 2003. Multi-parameter finger printing of sediment deposition in a small gullied catchment in SE Australia. Catena 53, 327-348.

Lagacherie, P., McBratney, A.B., Voltz, M., 2007. Digital soil mapping: an introductory perspective. Developments in Soil Science, 31. Elsevier, Amsterdam.

Le Bissonnais, Y., Thorette, J., Bardet, C., Daroussin, J., 2002. L'érosion hydrique des sols en France. Technical Report INRA et IFEN (63 pp.).

Martin, W.K.E., Timmer, V.R., 2006. Capturing spatial variability of soil and litter properties in a forest stand by landform segmentation procedures. Geoderma 132, 169-181.

Martínez-Casanovas, J.A., Ramos, M.C., Ribes-Dasi, M., 2005. On-site effects of concentrated flow erosion in vineyard fields: some economic implications. Catena 60, 129-146.

Martínez-Casasnovas, J.A., Ramos, M.C., 2006. The cost of soil erosion in vineyard fields in the Penedès-Anoia Region (NE Spain). Catena 68, 194-199.

Martínez-Zavala, L., Jordán, A., 2008. Effect of rock fragment cover on interrill soil erosion from bare soils in Western Andalusia, Spain. Soil Use Manag. 24, 108-117.

Martinez-Zavala, L., Jordán, A., Bellinfante, N., Gil, J., 2010. Relationships between rock fragment cover and soil hydrological response in a Mediterranean environment. Soil Sci. Plant Nutr. 56, 95-104.

McBratney, A.B., Santos, M.L., Minasny, B., 2003. On digital soil mapping. Geoderma 117 3-52.

Montgomery, D.R., Dietrich, W.E., 1994. A physically based model for the topographic control on shallow landsliding. Water Resour. Res. 30, 1153-1171.

Mulder, V.L., Bruin, S., Schaepman, M.E., Mayr, T.R., 2011. The use of remote sensing in soi and terrain mapping-a review. Geoderma 162, 1-19.

Paroissien, J.-B., Lagacherie, P., Le Bissonnais, Y., 2010. A regional-scale study of multidecennial erosion of vineyard fields using vine-stock unearthing-burying measurements. Catena 82, 159-168.

Poesen, J., Lavee, H., 1994. Rock fragments in top soils: significance and processes. Catena $23,1-28$.

Poesen, J., Ingelmo-Sanchez, F., Mucher, H., 1990. The hydrological response of soil surfaces to rainfall as affected by cover and position of rock fragments in the top layer Earth Surf. Process. Landf. 15, 653-671.

Poesen, J., Torri, D., Bunte, K., 1994. Effects of rock fragments on soil erosion by water at different spatial scales: a review. Catena 23, 141-166.

Poesen, J., Van Wesemael, B., Govers, G., Martinez-Fernandez, J., Desmet, P., Vandaele, K. Quine, T., Degraer, G., 1997. Patterns of rock fragment cover generated by tillage erosion. Geomorphology 18, 183-197.

Puigdefabregas, J., Alonso, J.M., Delgado, L., Domingo, F., Cueto, M., Gutierrez, L., Lazaro, R. Nicolau, J.M., Sanchez, G., Sole, A., Vidal, S., 1996. The Rambla Honda field site: interactions of soil land vegetation along a catena in semi-arid Southeast Spain. In: Brandt C.J., Thornes, J.B. (Eds.), Mediterranean Desertification a, d Land Use. Wiley, Chichester pp. $137-168$.

Quiquerez, A., Brenot, J., Garcia, J.P., Petit, C., 2008. Soil degradation caused by a highintensity rainfall event: Implications for medium-term soil sustainability in Burgundian vineyards. Catena 73, 89-97.

Schumacher, T.E., Lindstrom, M.J., Schumacher, J.A., Lemme, G.D., 1999. Modeling spatial variation in productivity due to tillage and water erosion. Soil Tillage Res. 51, 331-339.

Szilassi, P., Jordan, G., Van Rompaey, A., Csillag, G., 2006. Impacts of historical land use changes on erosion and agricultural soil properties in the Kali Basin at Lake Balaton, Hungary. Catena 68, 96-108.

Touriño Soto, I., 2005. Mise en relation de la cartographie du rendement avec la distribution spatiale de l'état de surface du sol observée par télédétection. Thèse de doctorat de Institut Nationale Polytechnique de Toulouse (250 pp.).

Wassenaar, T., Andrieux, P., Baret, F., Robbez-Masson, J.M., 2005. Soil surface infiltration capacity classification based on the bi-directional reflectance distribution function sampled by aerial photographs. The case of vineyards in a Mediterranean area. Catena 62, 94-110.

Webster, R., Oliver, M.A., 1990. Statistical Methods in Soil and Land Resource Survey Oxford University Press, Oxford.

Wischmeier, W.H., Smith, D.D., 1978. Predicting rainfall-erosion losses: a guide to conservation planning. Agricultural Handbook, 537. US Department of Agriculture, Washington, DC.

World reference base for soil resources, 2006. A framework for international classification, correlation and communication. World Soil Resources, Report No. 103. FAO Publication, Rome (142 pp.) 